\title{
GLOBALIZAÇÃO E SAÚDE: desafios para a Enfermagem em Saúde Coletiva no limiar do Terceiro Milénio
}

\author{
Maria Amélia de Campos Oliveira* \\ Maria Rita Bertolozzi* \\ Emiko Yoshikawa Egry** \\ Rosa Maria Godoy Serpa da Fonseca
}

RESUMO: Sob a influência dos processos mundiais de globalizaçăo e internacionalização dos mercados, a expansăo e a consolidaçăo do modelo econômico neoliberal no Brasil expressa-se também na área da saúde. Os indicadores de morbimortalidade traduzem os processos de exclusăo social que destituem a cidadania de 30 milhöes de brasileiros, situados abaixo da linha de pobreza, em uma evidente demonstraçăo de iniquidade. Alternativas para a construçăo e a proposiçăo de estratégias que permitam a superaçăo dessa realidade podem ser buscadas no arsenal teórico da Saúde Coletiva. Uma vez compreendido - conceito de saúde-doença que a embasa, sua ancoragem metodológica, os projetos de intervençăo que dela resultam, bem como a amplitude e a dinámica das mudanças que propöe, pode-se distingui-la da Saúde Pública. Para isso, impóese o resgate da historicidade da sua construção na década de 70 , como um movimento eminentemente político que se insurgiu contra a situaçăo social e política vigente na maioria dos países latino-americanos. Refazer esse movimento histórico, permite à Enfermagem melhor compreender a atual conjuntura para, assim, assumir seu papel social no processo de produçăo em saúde.

PALAVRAS-CHAVE: Enfermagem em Saúde Coletiva, globalizaçăo, processo de produçăo em saúde

\footnotetext{
* Professora Doutora do Departamento de Enfermagem em Saúde Coletive da Escola de Enfermegem da Universidede de Sza Paulo * Professora Titalar do Departamento de Exfermagem em Sáde Coletiva da Escola de Enfermagem da Universidade de Sto Paulo *** Professora Associada do Departamento de Enfermagem em Saúde Coletiva da Escola de Enfermegem da Universidado do Saso Paulo - Av. Dr. Enćas de Carvalho Aguiar, s/n Szo Paulo-SP CEP 05403-000
} 


\section{INTRODUÇÃO: O CENÁRIO}

O atual contexto sócio-econômico da sociedade brasileira, sob a influência dos processos mundiais de globalização e de internacionalização dos mercados, é consequiência da expansão e consolidação do modelo econômico neoliberal (IANNI, 1996). Na área da Saúde, seus resultados evidenciam-se nos indicadores de morbimortalidade, traduzindo os processos de exclusão social que destituem de cidadania 30 milhões de brasileiros, na mais evidente corporificação da iniqüidade.

Não há dúvida que o projeto governamental no terreno econômico é uma propositura neoliberal que postula a capacidade da iniciativa privada de resolver a crise econômica, complementado no terreno social por um discurso sobre o estado social e solidário que, no campo da saúde, diz preservar o ideário do Sistema Único de Saúde (SUS). Tal discurso não corresponde aos fatos e o que se verifica na prática é que tanto a política econômica como a social assentam-se sobre postulados neoliberais.

A concepção neoliberal propõe alcançar o bem-estar social incentivando ações das famílias, da comunidade e dos grupos privados, limitando a ação do Estado a aliviar a pobreza e a produzir aqueles serviços que o setor privado não quer produzir. Configurase assim um estado assistencialista e não de bem-estar, dado o caráter supletivo de suas ações frente à iniciativa privada.

Nessa concepção assistencialista de Estado apregoada pelo modelo neoliberal, a intervenção estatal está voltada para aliviar a pobreza com programas mínimos e seletivos, deixando o "grosso" do bem-estar social para o âmbito do privado. Suas estratégias para reduzir a ação estatal no terreno do bem-estar social são a privatização da produção dos serviços, os cortes dos gastos sociais, eliminando programas e reduzindo benefícios, a focalização dos gastos (destinando-os aos mais pobres, mediante a comprovação da pobreza - configurando uma condição da cidadania regulada), abandonando os critérios de universalidade e igualdade na formulação das políticas sociais (LAURELL, 1995).

Os valores da universalidade e da igualdade, por seu turno, levam a uma concepção distinta de bem-estar, baseada na idéia de que a sociedade (a coletividade) deve responsabilizar-se por prover e garantir um nivel satisfatório e igual de bem-estar para todos os seus membros, idéia estreitamente vinculada ao direitos de cidadania. Nesta concepção, as políticas sociais devem ser universais, abarcando todo o conjunto 
da população e provendo beneficios iguais para todos, e devem ser sobretudo políticas redistributivas, como um mecanismo para diminuir a desigualdade (LAURELL, 1995).

Esta posição sustenta o princípio de que o bem-estar social pertence à coisa pública e, como tal, compete à esfera estatal. Por outro lado, como os direitos sociais significam a satisfação de níveis de bem-estar compatíveis com o grau de desenvolvimento da sociedade, não devem se restringir ao minimo, mas podem e devem ser expandidos. Ou seja, as políticas sociais não devem ter como função única proteger os individuos da indigência e remediar a pobreza.

A análise da situação do setor saúde revela a necessidade de propor uma reorientação global das políticas de saúde, de modo a fazer cumprir a Constituição de 1988, em que a saúde é configurada como um direito de cidadania e um dever do estado, a partir de uma concepção social da saúde da coletividade. É sob esse marco que devem ser delineadas as estratégias para solucionar os problemas detectados. Trata-se, portanto, de fazer uma proposta para se contrapor à politica neoliberal e adotar medidas que contemplem as políticas sociais em geral e com impacto na saúde, que priorizem o fortalecimento e a expansão das instituições públicas com o objetivo de alcançar a universalidade e a igualdade, que impulsionem a transformação democrática e que aprofundem o papel redistributivo do estado para as classes trabalhadoras.

O desafio que se coloca, portanto, e não apenas para a Enfermagem, mas para a sociedade como um todo, é a proposição de alternativas que permitam a superação dessa realidade, cuja complexidade demanda mudanças radicais. Particularmente, cabenos refletir sobre um aspecto da questão social, no caso a política de saúde, entendendoa como parte das políticas sociais, guardando uma relação estreita com a política econômica nacional.

\section{O DISCURSO NEOLIBERAL E SUAS REPERCUSSÕES SOBRE A POLITICA DE SAÚDE}

Quando se observa a desigualdade crescente entre os distintos grupos sociais no que diz respeito ao acesso aos bens e serviços de saúde e entre o tipo e a qualidade dos serviços disponiveis para cada um desses grupos - identifica-se uma contradição flagrante com os princípios do Sistema de Saúde brasileiro, em especial o acesso universal. 
A demanda por serviços de saúde segue aumentando em virtude da extensão da cobertura, sem ser acompanhada pelo investimento dos recursos necessários. Sob os efeitos dessa ausência de recursos, uma das questões que tem se colocado referese à crescente diferenciação salarial dos trabalhadores inseridos no setor público e no setor privado. Essa situação tende a drenar do setor público o seu pessoal mais qualificado, canalizando-o para o setor privado. Basta observar a "evasão de cérebros" das universidades públicas, atraídos pelos melhores salários das escolas privadas, sem mencionar que muitos dos professores mais titulados têm antecipado suas aposentadorias, com receio de perder os benefícos sociais a que têm direito após anos de dedicação ao serviço público.

A crise laboral, entretanto, não se restringe aos salários, mas articula-se a um processo sistemático de desqualificação do trabalho realizado nas instituições públicas, como resultado da deterioração das condições de trabalho que, por sua vez, advém do aumento da cobertura dos serviços sem que aumentem os recursos necessários. E são os trabalhadores dessas mesmas instituiçöes públicas que quotidianamente têm que enfrentar a pressão dos usuários em busca de atendimento e as queixas sobre as deficiências dos serviços.

As restrições financeiras, o autoritarismo, a desqualificação e as más condições do trabalho têm provocado uma grave deterioração dos serviços das instituições públicas de saúde, e também de educação e têm contribuído para desprestigiá-las perante a sociedade. Certamente concorrem para tal descrédito da ação estatal o clientelismo, a burocratização, a ineficiência e a corrupção, diariamente estampadas nas manchetes de jornais. O equivoco do discurso privatizador, entretanto, é afirmar que a solução para tal estado de coisas reside em passar as funções estatais para o setor privado, sequer mencionando como alternativa de solução a sua transformação democrática e tecnicamente competente.

Contra esse ímpeto privatizante é preciso levantar alguns argumentos. O primeiro deles diz respeito ao fato de que a própria existência do setor privado erige-se como um obstáculo ao acesso universal a um serviço de saúde igualitário, pois opera com critérios de rentabilidade e sua lógica baseia-se não em prestar serviços a toda população, mas apenas aos que podem pagar. $O$ acesso aos serviços privados depende diretamente da capacidade econômica do usuário para absorver seus altos custos, frente à perda do poder de compra de amplos setores de trabalhadores assalariados ou que subsistem em subempregos, à margem do mercado formal. 
Um outro aspecto a considerar é que quando o setor privado cresce em importância, adquire a força política necessária para impedir a expansão do setor público, que passa a constituir uma ameaça aos seus interesses particulares. Com isso, cria obstáculos para a solução dos problemas de saúde de amplos contingentes da população, justamente aqueles que não podem pagar pela assistência.

Além disso, a lógica seletiva e de rentabilidade que move o setor privado imprime uma orientação curativa e não preventiva aos serviços, aumentando seu custo para a nação e para os indivíduos, pelo excesso de tecnologia. Os critérios de intervenção que adota, baseados mais na rentabilidade econômica que nas necessidades terapêuticas, acabam por induzir a utilização de métodos para o diagnóstico e cirurgias de eficácia duvidosa, aumentando as iatrogenias.

As implicaçōes políticas, sociais e econômicas do crescimento do setor privado, apenas esboçadas aqui, justificam porque é necessário pôr freios no processo de privatização dos serviços de saúde hoje em marcha, impedindo-o de realizar o que não é socialmente aceitável. Para isso é necessário submeter o setor privado a mecanismos estritos de regulação e supervisão, estabelecendo normas para o controle da qualidade dos serviços que presta, em complementação à ação estatal. Isso também inclui mecanismos específicos de controle sobre a indústria farmacêutica e de equipamentos, para reduzir seu alto custo e sua influência sobre o modelo de atenção.

Os argumentos utilizados nesta problematização devem ter tomado claro o caráter social da saúde, aqui entendida como a saúde da coletividade, um campo de práticas que responde a necessidades sociais.

Um projeto de saúde que se pretenda democrático e popular deve estar baseado em uma concepção que leve em conta os determinantes sociais do processo saúdedoença, entendendo que os problemas de saúde são uma expressão específica das condições de trabalho e de vida de distintos grupos sociais e que a sua solução deve articular-se com a transformação dessas mesmas condiçōes: as políticas de emprego e salários, de habitação, saneamento básico, de nutrição, de desenvolvimento urbano, a política agrária, a ecologia.

\section{AS RAIZZS HISTÓRICAS DA SAÚDE COLETIVA E A ENFERMAGEM COMO PRÁTICA SOCIAL: BREVE RETOMADA}

Toda política de saúde repousa sobre uma concepção, explícita ou implícita, de saúde e de doença (ABED, 1993). Dito de outra maneira: as formas como as sociedades 
identificam e explicam seus problernas de saúde e como se organizam para enfrentá-los variam em diferentes épocas históricas e dependem de determinantes estruturais econômicos, políticos e ideológicos. O caráter histórico das transformações está presente tanto na forma como se apreende teoricamente a saúde e a doença, quanto nas práticas prevalentes para a cura e o cuidado. Numa abordagem relativamente sumarizada, algumas mudanças nas idéias [e das práticas correspondentes] acerca da saúde e da doença podem ser visualizadas a seguir, destacando-se o aparecimento da Enfermagem moderna.

Ao longo da história, diferentes teorias interpretativas foram sendo forjadas como conseqüência da atividade racional humana em busca de inferências causais para a doença (CASTELLANOS; BERTOLOZZI, 1991). De acondo com CANGUILHEM (1978), da Antigüidade até o século XIX as formas de representação da doença podem ser reunidas em duas grandes vertentes, a ontológica e a dinâmica. A primeira delas atribui à doença um estatuto de causa única, uma entidade externa ao organismo humano e com existência própria, um mal de origem natural ou sobrenatural. Essa é a concepção presente entre os assírios, os caldeus, os egípcios e os hebreus na Antigüidade, freqüentemente vinculada a explicaçöes mágicas ou religiosas, que também orientavam as intervenções que objetivavam a cura. Apesar de todas as transformações históricas de que foi alvo, essa concepção ainda subsiste no pensamento contemporâneo (LUZ, 1979), na interpretação das doenças infecciosas e parasitárias, por exemplo, ou nas teorias genéticas (CANGUILHEM, 1978).

A concepção dinâmica de doença, por sua vez, identificável nas medicinas hindu e chinesa, é naturalista, na medida em que concebe a natureza, tanto interna como extemamente ao corpo humano, e harmônica, sendo que a doença advém do desequilíbrio ou da desarmonia entre os princípios ou forças vitais. Também entre os gregos prevalecia uma concepção dinâmica de saúde, entendida como um estado de isonomia ou equilíbrio entre os quatro elementos que compōem o corpo humano - a terra, o ar, a água e o fogo. A doença é naturalizada e passa a ser resultado do deseauilibrio ou disnomia e o ser 
distribuição das doenças à qualidade dos elementos naturais disponiveis (a água e o ar), ao espaço geográfico e às estações do ano'.

Na Roma Antiga, a enfermagem e a medicina eram exercidas por estrangeiros e escravos, pois era um trabalho indigno para os cidadãos (MELO, 1986).

Através dos tempos, o cuidado dos doentes foi exercido por diferentes categorias, sacerdotes, feiticeiros e mulheres até que se institucionalizasse a Enfermagem como profissão. No entanto, já existia uma certa distinção entre os que se ocupavam do cuidado dos ricos e dos pobres (PAIXÃO apud MELO, 1986:33).

As mulheres sempre foram curandeiras em todas as épocas, já que o cuidado ao doente era feito em casa e prestado quase sempre por mulheres. Na sua origem, "a enfermagem estava associada ao trabalho feminino, pouco valorizado socialmente, de acordo com o papel designado à mulher pela sociedade de classe". Com o advento das ordens seculares, no século XIII, a enfermagem adentrou os hospitais, através das religiosas. O trabalho da enfermagem, exercido pelas religiosas, sem conhecimentos próprios que pudessem fundamentar a prática, assim permaneceu mesmo quando a prática médica transformou-se em técnico-profissional (MELO, 1986).

Ao longo de toda a Idade Média, atternaram-se concepções ontológicas e dinâmicas das doenças, embora seja possivel dizer que houve um predomínio da concepção dinâmica até o final do século XVIII, através da Teoria Miasmática ${ }^{2}$. No entanto desde o século XVI, Fracastoro esboçara uma teoria do contágio, vinculada à vertente ontológica, ao aventar a hipótese da existência de partículas invisíveis, que ele denominou seminária (de semente), que seriam responsáveis pela transmissão das doenças, por contágio direto, pessoa a pessoa, ou indireto, através dos objetos utilizados por pessoas doentes (BARATA, 1990).

\footnotetext{
1 Acredita-se que tenha sido ele o primeiro a utilizar as palavras endemeion (doenças próprias de uma commidade, ou endêmicas) e epidemeion (doenças que visitam a comunidade ou epidemias), sendo que essa última teria dado origem ao termo epidemiologia, ou seja, estudo da ocorrência das doenças em uma comunidade.(NAJERA, 1991)

2 Teoria Miasmática: a doença adviria de miasmas, vapores ou emanações dos pântanos, dos dejetos, das águas contaminadas. Sob sua influência, vários estudos foram feitos relacionando o ambiente e a distribuiçăo das doenças nas populaçox. (CZERESNIA, 1997) Durante a Idade Média, sob o modo de produçao feudal e o domínio da Igreja, poucos foram os avanços no campo da saúde. Ainda que mantidos os princípios hipocráticos, o Cristianismo levou ao um abandono progressivo da prática clínica, pois a preocupaço maior era a salvaça do espírito. $O$ grande número de epidemias que assolou a Europa nesse periodo fez com que as preocupapöes se voltassem para as doencas transmissíveis, então atribuídas a influências cósmicas, à bruxaria ou ao envenenamento da água e do ar por grupos estigmatizados, como judeus e leprosos (ANDERY et al., 1988).
} 
No século XVI, a Reforma Protestante trouxe transformaçöes importantíssimas no modo como as sociedades ocidentais se organizavam para a produçäo de sua existência cujas conseqüências para a enfermagem foram muito intensas que aquelas devidas às conquistas da Medicina, uma vez que as práticas mantinham certo paralelismo no que dizia respeito às teorias condutoras da internalidade dos processos de trabalho.

Desde o século XVII, a ciência médica progredira consideravelmente, com o desenvolvimento da Anatomia e Fisiologia humanas, graça às cuidadosas observações de Vesálius na dissecação de cadáveres, assim como pela evolução da Patologia, que estabeleceu um sistema classificatório para as doenças. Juntas, a Anatomia, a Fisiologia e a Patologia permitiram o que Foucault chamou de "o nascimento da clínica" (FOUCAULT, 1977).

Entretanto, com a Revolução Industrial que se iniciara na Inglaterra, dali se disseminando por toda a Europa, agravaram-se muito as condições de saúde das populaçōes que haviam sido atraídas para as cidades ao longo dos séculos XVIII e XIX. A escassez de água potável, a ausência de saneamento, as habitaçōes precárias e a exploração do trabalho que caracterizam a fase inicial da industrialização repercutiram intensamente sobre as condiçőes de vida e saúde desses aglomerados urbanos. Esboçaram-se assim as primeiras evidências da determinação social do processo saúdedoença e formularam-se os primeiros modelos estatais de interferência na saúde das coletividades, entre eles a Saúde Pública inglesa e a Medicina Social francesa (SILVA, 1979).

O projeto da Saúde Pública, tal como ainda ocorre, preconizava a ação supletiva do Estado, de forma sempre limitada e complementar à iniciativa privada, para solucionar os problemas dos que viviam em condiçöes de extrema pobreza, os desvalidos, sempre que a situação excedesse as possibilidades de intervenção individual. Veja-se que aqui encontram ressonância os pressupostos do projeto neoliberal. Já a Medicina Social francesa fundava-se no reconhecimento das relaçöes existentes entre a doença $e$ as condiçōes sociais, desenvolvendo-se mais lentamente que a Saúde Pública e institucionalizando-se nos "estados de bem-estar social" modemos (SILVA, 1979).

Para MACHADO (1978:248), "a característica mais geral dessa transformaçăo e o fato da medicina se tomar social. [A partir dai] a prática médica náo deve mais se restringir a considerar a doença isoladamente e a atuar sobre ela depois que tenha eclodido. O fundamental náo é a açăo direta sobre a doença para restabelecer a saúde, 
mas antes de tudo, impedir o seu aparecimento, controlar a sua manifestaçăo. O objeto da medicina começa a se destocar, portanto, da doença para a saúde."

A Enfermagem Modema surgiu nessa época, na tentativa de organização do espaço de cura - no que haviam se transformado os hospitais - inaugurando a era "nightingaleana". As novas bases da profissão iniciaram-se vinculadas à guerra e sob a égide do capitalismo. A prática da enfermagem era orientada pelos pressupostos da teoria predominante em saúde, mais do que isto, a recuperaçäo dos corpos para o trabalho na inaugurada era industrial já se fazia presente.

Mas uma outra transformação estava em curso. Até o final do século XVIII os paradigmas sócio-ambientais predominavam como forma de explicação da doença e a miséria e os miasmas eram invocados para explicar a disseminação das enfermidades. Mas quando as tentativas de explicar o contágio resultaram na compreensão de que pequenas partículas invisiveis eram responsáveis pela propagação das doenças, foi retomada a vertente ontológica de causalidade, suplantando a concepção mais totalizante que apreendia a doença como resultado da interação de inúmeros fatores, entre eles 0 ambiente $e$ as condições sociais (CZERESNIA, 1997).

Iniciava-se assim a Era Bacteriológica, concretizada pelas descobertas de Pasteur e Koch, fundamentais para a cura das doenças infecciosas. A revolução científica desencadeada pela Bacteriologia levou ao abandono das consideraçöes sociais, lançando as bases da Medicina moderna: 0 combate às doenças infecciosas através da vacinação e do tratamento clínico, a ênfase na definição biológica das doenças (a fisiopatologia) e a crença na possibilidade de sua erradicação (ROSEN,1994; BANTA; DAHUCE,1993).

Entretanto, a teoria unicausal, mesmo quando aplicada às doenças infecciosas, em pouco tempo mostrou-se insuficiente para explicar toda a complexidade do adoecer humano. É certo que a presença de um agente é causa necessária para provocar a doença, mas nem sempre é causa suficiente, pois não explica porque determinados grupos sociais são mais vulneráveis ao adoecimento que outros. Para responder a essa questão desenvolveu-se a teoria multicausal, baseada na interação entre 0 agente, 0 hospedeiro e o ambiente. Esse modelo teórico possibilitou inúmeros avanços na compreensão das doenças infecciosas.

3 Florence Nightingale organizou o hospital militar na Guerra da Criméia. 
Nesse interim, Medicina e Enfermagem, duas práticas até então independentes, haviam sido reunidas no hospital - espaço de cura, ficando a enfermagem subaltemizada em relação à medicina. Os avanços tecnológicos, ao lado das políticas de saúde haviam ampliado a divisão social do trabalho, criando novas categorias para se ocupar do cuidado direto. "A divisão social do trabalho na enfermagem, não surgiu por acaso e nem se mantém pela tradição, mas como forma de adaptação da estrutura organizacional ao modo de produção dominante". Reflete, isso sim, a própria organizaçăo do processo de trabalho, em uma sociedade de classes, manifestando as diferentes formas de propriedade e desigualdade social (MELO, 1986).

Com a Enfermagem modema, o cuidado paulativamente abandona a finalidade religiosa e passa a ter a finalidade de controle do ambiente do doente tendo na disciplina o elemento-chave para normatizar e regulamentar a vida hospitalar (ALMEIDA; ROCHA, 1986). Na primeiras décadas do século $X X$ surgem as primeiras manifestações organizadas e sistematizadas do saber da enfermagem, constituidas pelas técnicas de enfermagem4.

$\mathrm{Na}$ arena do saber da medicina o modelo da balança criado por Gordon na década de 20, em que a doença aparece como resultante do desequilíbrio de múltiplos fatores, a multicausalidade passou por uma série de atualizações. Na década de 40, nos Estados Unidos, a Medicina Integral definiu o ser humano como um ser bio-psico-social. A Teoria Ecológica de Leavell e Clark também representou uma variante mais dinâmica e desenvolvida do modelo multicausal, em que a prevenção se faz com base na História Natural da Doença (BARATA,1990).

Mas foi somente após a II Guerra Mundial, quando já se havia conseguido um controle relativo das principais doenças transmissiveis, que a abordagem social do fenômeno saúde-doença foi retomada, frente à constatação de que um contingente expressivo de individuos pertencentes às classes sociais menos favorecidas permanecia à margem desses avanços, em precárias condiçōes de vida e de saúde.

O avanço tecnológico da prática médica levara à especialização, à ênfase nos procedimentos complementares e à elevação dos custos da assistência, reduzindo seu alcance social, pois a assistência tornara-se acessivel apenas para um número restrito

4 Técnicas consistem na descriço passo a passo do procedimento de enfermagem e especificam a relaçăo do material a ser utilizado, que tanto podem ser as relativas ao cuidado dircto quanto às rotinas administrativas (ALMEIDA;ROCHA, 1986). 
de pessoas e não para o coletivo. Havia, como ainda há, uma incongruência entre os avanços tecnológicos e as questões sociais. Na teoria da multicausalidade, a pobreza e o subdesenvolvimento passam a ser responsáveis pela ocorrência das doenças.

\section{A ENFERMAGEM EM SAÚdE COLETIVA E OS DETERMINANTES DAS TRANSFORMAÇÕES DAS TRÊS ÚLTIMAS DÉCADAS}

Na América Latina dos anos 70, em um momento de profunda crise econômica e social, semelhante àquela vivenciada nos paises europeus ao final do século XVIII e início do século XIX, aprofundada por uma intensa repressão política e ideológica, retomou-se a discussão da determinação social do processo saúde-doença (NUNES, 1986). Esse movimento surgiu como uma crítica ao modelo ecológico e teve como objetivo orientar novas formas de intervenção em saúde voltadas para as classes subalternas (CASTELLANOS, 1985; STOTZ, 1997; TEIXEIRA, 1985). Surgiu assim a Saúde Coletiva, cujas raizes históricas remontam à Medicina Social francesa e que assim se denomina para se distinguir da Saúde Pública, com a qual tem profundas diferenças.

A enfermagem assumiu, a partir dessa década maior enfoque assistencial (GERMANO, 1983) e sua produção científica espelha esta inflexão, privilegiando a área assistencial, com predominância dos aspectos relativos às áreas médico-cirúrgica e administrativas. A enfermagem de saúde pública, tanto por parte das instituições de serviços quanto das escolas, do mesmo modo que a Saúde Pública "foi marginalizada pelo Estado (...) enquanto pauta da agenda das políticas públicas (ou seja, como um campo de investimentos financeiros, de aplicação de recursos humanos e materiais e inversão para a construção de conhecimentos)" . "As pesquisas em enfermagem concentraram-se naquelas que davam suporte ao cuidado sob o prisma da dicotomizada medicina "curativa-preventivista" (..) que sofisticavam cada vez mais a intenvenção intrahospitalar (...)" (EGRY, 1996).

Na década de oitenta, a despeito dos avanços das discussões em termos da reorganização do setor saúde e da enfermagem como prática profissional, prevaleceu a tendência anterior, ou seja, da visão de saúde biologicista e centrada no indivíduo, ou quando muito, a concepção multicausal do processo saúde-doença.

"No mesmo periodo, destacam-se as mudanças importantes no cenário nacional: o crescimento populacional, o aumento da participação da mulher na força de trabalho, a aceleração do processo de urbanização, o aumento da população economicamente 
ativa no setor de produção industrial e de serviços e o aumento de emprego no setor público, que passou da cifra de $20 \%$ até a década de 70 , para $60 \%$ na década de 80 " (SENA-CHOMPRÉ; EGRY, 1998:31).

As questões relativas ao entendimento do processo saúde-doença socialmente determinado, base teórico-ideológica da Saúde Coletiva - e por conseguinte de sustentação do Sistema Único de Saúde -, começaram a difundir-se na Enfermagem principalmente no interior da academia, através da participação da categoria nos movimentos da Reforma Sanitária e outros movimentos sociais, tal como o movimento feminista. Mesmo assim, até hoje a Enfermagem (na teoria e na prática) apresenta dificuldades em distinguir com clareza as diferenças teórico-conceituais entre a Saúde Pública e Saúde Coletiva, tal como foi debatido por Breilh e re-afirmado por EGRY (1996).

\section{AS VULNERABILIDADES TEÓRICO-CONCEITUAIS: PERSPECTIVAS PARA A ENFERMAGEM NA ERA DA GLOBALIZAÇÃO}

A Enfermagem, como parte do processo de produção em saúde, é determinada pelos mesmo paradigmas que regem o conjunto das práticas no campo da saúde e sujeita às mesmas visões do processo saúde-doença, que necessita reformular (SALUM et al., 1998).

Entretanto, a questão dos paradigmas encontra-se na atualidade em pleno processo de revisão e também tem sido objeto de estudos da Enfermagem. Verifica-se, por exemplo que há uma pluralidade paradigmática no campo da saúde, o que torna relativamente complicada a pouca ênfase que os pesquisadores da saúde (e da Enfermagem) têm dado a esta importante dimensão na aproximação dos fenômenos, tanto na pesquisa quanto na intervenção (EGRY, 1996 e EGRY, 1998).

Assumir os pressupostos teóricos da Saúde Coletiva significa admitir que na sociedade há práticas de desigualdade, recusando a concepção idealista de uma sociedade igualitária. Significa ademais assumir a politicidade da prática em saúde, negando a sua suposta neutralidade científica. Tal politicidade somente será transformadora se for assegurada a participação popular na formulação das políticas de saúde, para garantir a obtenção de benefícios diferenciados por classe social, gênero, raça/etnia e geração (FONSECA; BERTOLOZZI, 1997). 
Frente ao reconhecimento da importância do engajamento da população na luta pela transformação social, cabe à Enfermagem buscar estabelecer canais de comunicação direta com os grupos organizados da comunidade, de modo a identificar realidades que escapam à fala autorizada, ampliando assim o "cardápio das necessidades de saúde" (SCHRAIBER, MENDES-GONÇALVES, 1996), criando ou apropriando-se de instrumentos que permitam intervir na dimensão coletiva do processo saúde-doença e recriando relações mais democráticas com os usuários dos serviços de saúde, com os trabalhadores da equipe de enfermagem e com os demais trabalhadores da Saúde (CAMPOS, 1994).

Cabe-lhe ainda produzir conhecimentos que levem em conta a determinação social dos fenômenos da saúde e da doença, entendidos como pólos complementares de um processo dialético que se expressa tanto no corpo biopsíquico individual como nos perfis epidemiológicos dos distintos grupos sociais.

No trabalho da Enfermagem há ainda um outro aspecto a ressaltar, o fato de que se trata de uma profissão eminentemente feminina que se caracteriza por uma prática historicamente vinculada à função social da mulher - 0 cuidar, o que a submete a uma dupla subordinação - social, ao trabalho médico, e de gênero, ao masculino (FONSECA, T., 1996).

Assim sendo, além dos inúmeros desafios colocados pela Saúde Coletiva na defesa intransigente da equidade, cabe à Enfermagem redefinir sua prática assistencial e de ensino, na luta pela transformação da sua subalternidade social (FONSECA, R., 1996). Para tanto, cumpre transformar os conteúdos e os métodos de qualificação da força de trabalho em Enfermagem, incluindo as necessárias reflexões sobre as especificidades do trabalho de cada categoria funcional, com ênfase na condição feminina.

\section{REFERÊNCIAS BIBLIOGRÁFICAS}

ABED, L.C. La enfermedad en la historia: una aproximación política, cultural e socioeconómica. Cordoba, Universidad Nacional de Córdoba, 1993.

ALMEIDA, M.C.P.de; ROCHA, J.S.Y. O saber da enfermagem e sua dimensåo prática. São Paulo, Cortez, 1986. 
ANDERY, M.A. et al. Para compreender a ciencia: uma perspectiva historica. Rio de Janeiro, EDUC-Espaço e Tempo, 1988.

BANTA, D.; DAHUCE, B.R. Health care technology and its assessment. an intemational perspective. Oxford, Oxford University Press, 1993. cap.2.

BARATA, C.B. A historicidade do conceito de causa. In: ESCOLA NACIONAL DE SAÚDE PÚBLICA. Epidemiologia 1: textos de apoio. 2 ed. Rio de Janeiro, ENSPIABRASCO, 1990.

BREILH, J.; GRANDA, E. Investigaçăo da saúde na sociedade: guia pedagógico sobre um novo enfoque do método epidemiologico. São Paulo, Instituto da Saúde/ ABRASCO, 1986.

CAMPOS, G. W. S. Considerações sobre a arte e a ciência da mudança: revolução das coisas e reforma das pessoas: o caso da saúde. In: CECíliO, L. C. de O. org. Inventando a mudança na saúde. São Paulo, Hucitec, 1994.

CANGUILHEM, G. O normal e o patolbgico. Rio de Janeiro, Forense-Universitária, 1978.

CASTELLANOS, B. E. P.; BERTOLOZZI, M. R. A questão das teorias interpretativas da "saúde" e da "doença". São Paulo, 1991. [mimeografado].

CASTELLANOS, P.L. As ciências sociais em saúde na Venezuela. In: NUNES, E.D., ed. As ciências sociais em saúde na América Latina: tendencias e perspectivas. Brasília, OPAS, 1985. p. 137-54.

CZERESNIA, D. Do contágio à transmissáo: ciência e cultura na gênese do conhecimento epidemiológico. Rio de Janeiro, FIOCRUZ, 1997.

EGRY, E.Y. Enfermagem em saúde coletiva: das categorias de análise e interpretação. São Paulo. Escola de Enfermagem da Universidade de São Paulo, 1998. [mimeografado]

EGRY, E.Y. Saúde coletiva: construindo um novo método para a enfermagem. São Paulo. Ícone, 1996.

FACCHINI, L.A. Por que a doença? : a inferência causal e os marcos teóricos de análise. In: ROCHA, L.E.; RIGOTO, R.M.; BUSCHINELLI, J.T.P. org. Isto e trabalho de gente?: vida, doença e trabalho no Brasil. Petrópolis, Vozes, 1994.

FONSECA, R.M.G.S. da F. Mulheres e enfermagem: uma construção generificada do saber. São Paulo, 1996. [Tese de Livre-docência - Escola de Enfermagem da USP].

FONSECA, R.M.G.S. da F.; BERTOLOZZI, M. R. A epidemiologia social e a assistência à saúde da população. In: ASSOCIAÇÃO BRASILEIRA DE ENFERMAGEM. A 
classificaçáo das praticas de enfermagem em saúde coletiva e o uso da epidemiologia social. Brasília, 1997. p. 1-59 (Série Didática: Enfermagem no SUS).

FONSECA, T.M.G. De mulher a enfermeira: conjugando trabalho e gênero. In: LOPES, M. J. et al. Género e saúde. Porto Alegre, Artes Médicas, 1996. p. 62-75.

FOUCAULT, M. O nascimento da clinica. Rio de Janeiro, Forense Universitária, 1997.

GERMANO, R. Educaçăo e ideologia da enfermagem no Brasil. São Paulo, Cortez, 1983.

IANNI, O. A era do globalismo. Rio de Janeiro, Civilização Brasileira, 1996.

LAURELL, A C.; NORIEGA, M. Processo de produçåo em saúde: trabalho e desgaste operário. São Paulo, Hucitec, 1989.

LAURELL, A. C., org. Estado e polfticas sociais no neoliberalismo. São Paulo, Cortez, 1995.

LUZ, M.T. As instituiçoes médicas no Brasil: instituiçáo e estratégia de hegemonia. Rio de Janeiro, Graal, 1979.

MACHADO, R. et al. Danaçáo da norma: a medicina social e a constituiçăo da psiquiatria no Brasil. Rio de Janeiro, Graal, 1978.

MELO, C. Divisăo social do trabalho e enfermagem. São Paulo, Cortez, 1986. 94p.

NAJERA, E. Discussión In: BUCK, C. El desafio de la epidemiología: problemas y lecturas selecionadas. 2 ed. Washington, DC, OPAS/OMS, 1991. p.3-17. (Publicación Cientifica n.505).

NUNES, E.D., org. Ciencias sociales y salud en la America Latina: tendencias y perspectivas. Montevideo, OPS/CIESU, 1986.

ROSEN, G. Uma historia da saúde pública. São Paulo, Hucitec, 1994.

SALUM, M. J. L., BERTOLOZZI, M. R., OLIVEIRA, M. A. de C. O coletivo como objeto do conhecimento e da prática de enfermagem: as continuidades e descontinuidades da história. São Paulo, Escola de Enfermagem da Universidade de São Paulo, 1998. [mimeografado]

SCHRAIBER, L.B. ; MENDES-GONÇALVES, R.B. Necessidades de saúde e atenção primária. In: SCHRAIBER,L.B. et al., org. Saúde do adulto: programas e açóes na unidade básica. São Paulo, Hucitec, 1996. p.29-46. 
SILVA, G.R. As origens da medicina preventiva como disciplina do ensino médico. Rev. Hosp. Clin. Fac. Med. USP,.28:91-4, 1979.

SENA-CHOMPRE, R.R.; EGRY, E.Y. A enfermagem no Projeto UNI: redefinindo um novo projeto político para a enfermagem brasileira. São Paulo, HUCITEC, 1998.

STOTZ, E.N. A saúde coletiva como projeto científico: teoria, problemas e valores na crise da modernidade. In: CANESQUI, A. M., org. Ciencias sociais e saúde. São Paulo, Hucitec, 1997. p. 274-84.

TEIXEIRA, S. M. F. As ciências sociais em saúde no Brasil. In: NUNES, E.D. (ed.). As ciencias sociais em saúde na América Latina: tendências e perspectivas. Brasília, OPAS, 1985. p. 87-109.

\title{
GLOBALIZATION AND HEALTH: challenges for Collective Health Nursing in the edge of the Third Millenium
}

\begin{abstract}
SUMMARY: Under the influence of the world processes of globalization and internationalization of markets, the expansion and consolidation of the neoliberal economic model are also expressed in Brazil in the health field. The morbidity and mortality indicators translate the processes of social exclusion that deprive the citizenship of at least $\mathbf{3 0}$ million Brazilians placed below the poverty line, in a clear expression of inequality. Alternatives for the construction and proposition of strategies that allow the overcoming of such reality can be searched for in the theoretical body of Collective Health. Once understood the concept of health-disease that underlies it, its methodological anchorage, the resulting intervention projects, as well as the width and the dynamics of the changes that it proposes, it can be distinguished from Public Health. This approach points out the need to re-build the history of Collective Health in the 70's, as a political movement against the social and political situation in most of the Latin American countries. The reconstruction of this historical movement allows Nursing to better understand the current conjuncture in order to assume social role in the health production process.
\end{abstract}

KEY WORDS: Collective Health Nursing; globalization; health production process

Recebido em 31/08/98

Aprovado em 12/12/98 